\title{
Clinico-radiologic features of four cases of Ameloblastoma
}

\author{
Al-Salihi K A ${ }^{1 *}$, Ihsan Abdullah², Ling Yoke $\mathrm{Li}^{3}$
}

'College of Veterinary Medicine/ Al Muthanna University / Formerly senior lecturer/ School of

dental sciences/Universiti Sains Malaysian

${ }^{2}$ College of dentistry /Al Muthanna University

${ }^{3}$ School of Dental Sciences/ Universiti Sains Malaysia
Corresponding author: E-mail:mrvsa59@gmail.com

Received: October 06, 2017

Accepted: January 25, 2018

Ameloblastomas are jaw tumors that are locally aggressive with a high capacity for recurrence. It arises from the epithelium of the dental lamina. Radiograph remains the first and an essential investigation, despite the development of various cross-sectional imaging modalities. Aim: This article intends to describe the clinical findings and orthopantomograph (OPG) supported by computed tomography scan (CT scan) and MRI of four cases of ameloblastomas in the hospital University Sains Malaysia. Materials and methods: Data concerning the patients' ages, sex, tumor locations, and surgical treatment history, as well as the radiographic findings, were analysed. Results: The patients' ages ranged from 23 to 41 years (mean, 30.5 years). The gender of patients were two male (50\%) and 2 (50\%) females. Three cases (75\%) of ameloblastomas located in the mandible and only one case found in the maxilla. The swelling was the most common symptom and experienced by all patients. Radiographically, two cases were unilocular with a well-demarcated border, and the remaining 2 cases were multilocular. Typical features of unicystic ameloblastoma appeared in case 1 . This case previously presented with a lesion in the same area diagnosed as a dentigerous cyst. The other 3 cases showed variant types of ameloblastoma. These were Plexiform, Acanthomatous and Granular cell type; follicular and plexiform type; and follicular and plexiform type in case 2, 3 and 4 respectively. Conclusion: In conclusions, determination the location and density of jaws lesion and its margin relation to the tooth using radiological tool accompanied with clinical data, aids in the narrowing of the differential diagnosis and it is necessary for early diagnosis of ameloblastoma. A Long-term follow-up at regular intervals after surgery is recommended for all ameloblastomas cases.

Keywords: Radiograph. Universiti Sains Malaysia. Unicystic ameloblastoma. Jaws 


\section{Introduction}

Ameloblastoma is the most common epithelial benign odontogenic tumor that can be locally aggressive and invasive. It represents only $1 \%$ of tumors arising in the jaws $1,2,3$. It develops from various sources of odontogenic epithelium, including residual epithelium from tooth germ, the stratified squamous epithelium, the epithelium of odontogenic cysts and the enamel organ epithelium ${ }^{4}$. Ameloblastoma appears most commonly in the third to fifth decades. Over $80 \%$ occur in the mandible, with $70 \%$ of these arising in the molar-ramus area, and they are occasionally associated with unerupted third molar teeth. They are usually benign in growth pattern but frequently invade locally and seldom metastasize. Because of their neoplastic nature, surgical treatments differ from those of other cystic lesions. Ameloblastoma is usually resected en bloc and sometimes with hemimandibulectomy or partial maxillectomy, if the lesion is highly infiltrative and extensive. Therefore, a precise preoperative diagnosis has important therapeutic implications. Several studies regarding clinicopathological characteristics of ameloblastoma reported in Thailand ${ }^{5}$, Singapore ${ }^{6}$, and Japan ${ }^{7}$.

Most cases of ameloblastoma have a characteristic radiographic appearance although it is not diagnostic. Radiographically, ameloblastomas described as a multilocular or unilocular cyst-like lesion. They are typically radiolucent and rounded areas, with moderately well-defined margins. Lingual expansion may sometimes be seen, but it is not pathognomonic of ameloblastoma. Other variants are a honeycomb pattern, a single well-defined cavity indistinguishable from a radicular, or rarely, a dentigerous cyst ${ }^{8}$. Four radiographic features are significant in ameloblastoma these include the expansion of the cortical plate, the presence of corticated scalloped margin, the multilocular appearance of the lesion, and the resorption of the adjacent roots of teeth ${ }^{9}$.

In Malaysia, the distribution of this tumor reported in children ${ }^{10}$ moreover, separated case studies have also been published ${ }^{11}$. Siar and $\mathrm{Ng}(1993)^{12}$ mentioned that radiological features of the multilocular type were the most common, followed by unspecified type, unilocular and mixed radiolucent-radiopaque lesions. In their review, Reichart et al. (1995) ${ }^{13}$ indicated that the frequent radiographic findings were embedded tooth, root resorption, and undefined borderline. Approach to treatment of ameloblastoma is controversial and can be changed with the clinical-radiologic variant, anatomic location and clinical behaviour of a tumour. In addition, the age and the general state of health of the patient are important factors. This article intends to describe the clinical and OPG features supported by CT scan and MRI of four cases of ameloblastomas in the hospital university Sains Malaysia.

\section{Material and methods}

\section{Patients}

The study comprised of 4 patients of ameloblastomas ( 1 unicystic type and 3 variant types). These cases were referred to the school of dental sciences/ Universiti Sains Malaysia (Hospital of Universiti Sains Malaysia / Health campus, Kelantan) with a painless swelling in the jaws. The OPG was done for all patients as one of the diagnostic tools. Moreover, the patients were also admitted to CT scan and MRI. 


\section{Ethical approval}

This research has been approved by the Ethics and Research Committee, with reference USMKK/PPSP $® /$ tindakan minit 149.6.

\section{Results}

Clinical findings and radiological presentation

\section{Case 1 /Unicystic Ameloblastoma}

This case was a unicystic ameloblastoma in 27 years aged female affecting the left maxilla. The patient had swelling over the palatal region for six years. The swelling size was increased gradually over the past two years. It was non-tender, painless, no bleeding and ulceration. However, there was teeth mobility adjacent to the area of swelling. She also had a nasal blockage, rhinorrhea, and epiphora. Patient's nose deformed due to the massive growth of the tumor. She had no palpable cervical lymph node and no history of malignancy. However, she previously diagnosed with a dentigerous cyst in the same area of the current growth.

The radiological findings showed unilocular tumor with a smooth margin and associated with a resorbed root of the 1st premolar and the expansion of the left palatal arch. Displaced tooth of the upper left quadrant also was present. Tumour was enlarged causing severe facial deformity. It extended into the nasal septum and paranasal sinuses, causing marked nasal obstruction. Extension into the orbital floor of maxilla bone also seen. Coincidently, ameloblastoma in this patient originated from a previous dentigerous cyst (Figure 1) (Table 1).
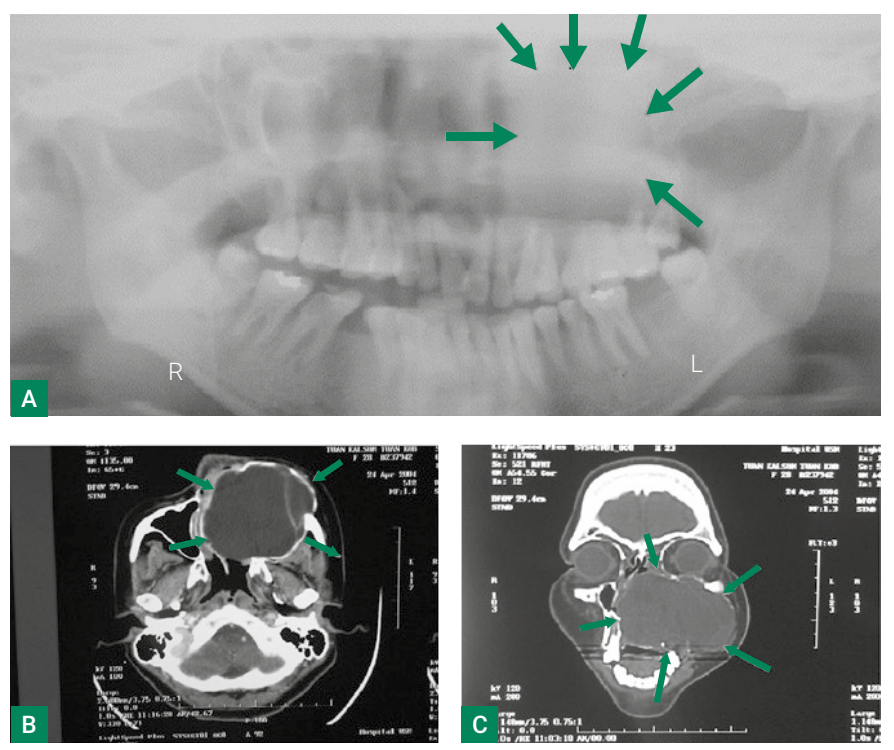

Figure 1. Shows the unicystic Ameloblastoma. (A) OPG showed a large area of unilocular radiolucency, showing teeth displacement and root resorption on 24. (B) Coronal CT scan shows a large unilocular mass compressing the nasal septum, nasal passage and left maxillary sinus. (C) Coronal CT scan showed a large mass on the left cheek extending into the oral cavity, nasal airway, maxillary sinus, left orbital floor and surrounding soft tissue. 
Table 1. Shows the clinical and radiological findings and diagnosis of ameloblastomas

\begin{tabular}{|c|c|c|c|c|c|}
\hline Case $\mathrm{N}^{\circ}$ & $\begin{array}{l}\text { Age/ years } \\
\text { and sex }\end{array}$ & Location & Clinical findings & Radiological findings & Diagnosis \\
\hline 1 & 27 / Female & $\begin{array}{c}\text { left } \\
\text { maxilla }\end{array}$ & $\begin{array}{l}\text { Previous history of } \\
\text { dentigerous cyst, swelling } \\
\text { of the palatal region non- } \\
\text { tender, painless, no bleeding } \\
\text { and no ulceration, teeth } \\
\text { mobility adjacent to the area } \\
\text { of swelling, nasal blockage, } \\
\text { rhinnorrhea epiphora, } \\
\text { previously diagnosed } \\
\text { with a dentigerous cyst } \\
\text { of the same area with the } \\
\text { current growth. }\end{array}$ & $\begin{array}{l}\text { unilocular, smooth margin, } \\
\text { resorbed root of the } 1 \text { st } \\
\text { premolar, expansion of } \\
\text { the left palatal arch, severe } \\
\text { facial deformity, extension } \\
\text { into the nasal septum and } \\
\text { paranasal sinuses, marked } \\
\text { nasal obstruction and } \\
\text { extension into the orbital } \\
\text { floor of maxilla bone }\end{array}$ & $\begin{array}{c}\text { Unicystic } \\
\text { Ameloblastoma }\end{array}$ \\
\hline 2 & $31 /$ female & $\begin{array}{c}\text { left } \\
\text { mandible }\end{array}$ & $\begin{array}{l}\text { Swelling of chin, mobile } \\
\text { teeth at the surrounding } \\
\text { area, subsequently the } \\
\text { teeth were extracted, } \\
\text { socket never healed, } \\
\text { palpable small lymph } \\
\text { nodes with multiple } \\
\text { mucosa ulceration on the } \\
\text { buccal cheek. }\end{array}$ & $\begin{array}{l}\text { Tumour extended into } \\
\text { surrounding tissues and } \\
\text { caused bony destruction. It } \\
\text { was a multiloculated mass } \\
\text { on the left jaw extending into } \\
\text { the left maxillary sinus and } \\
\text { expanding the buccal cortex } \\
\text { of the lower left mandible. }\end{array}$ & $\begin{array}{c}\text { Variant } \\
\text { Ameloblastoma }\end{array}$ \\
\hline 3 & $41 /$ male & mandible & $\begin{array}{l}\text { swelling over anterior lower } \\
\text { jaw, numbness of the lower } \\
\text { lip, mobile teeth Grade I. } \\
\text {,painless and non-tender, } \\
\text { non-compressible }\end{array}$ & $\begin{array}{l}\text { multiloculated radiolucency } \\
\text { extending from } 33 \text { to } \\
44 \text {. No well-defined } \\
\text { margins, presence of roots } \\
\text { resorption adjacent to } \\
\text { the tumour, expanded the } \\
\text { lingual cortex. }\end{array}$ & $\begin{array}{c}\text { Variant Type } \\
\text { Ameloblastoma }\end{array}$ \\
\hline 4 & 23/ male & mandible & $\begin{array}{l}\text { a painless, swelling,bony } \\
\text { hard, non-tender, fixed } \\
\text { to underlying structure } \\
\text { overlying the skin. }\end{array}$ & $\begin{array}{l}\text { Well defined uniloculated } \\
\text { radiolucency, smooth } \\
\text { borders, displacement } \\
\text { of teeth } 45 \text { and } 46 \text {, slight } \\
\text { expansion of cortex. }\end{array}$ & $\begin{array}{c}\text { Variant Type } \\
\text { Ameloblastoma }\end{array}$ \\
\hline \multirow{4}{*}{ Summary } & Age's range: & \multicolumn{4}{|c|}{ 23-41 years \& Age average: 30.5} \\
\hline & Sex: & \multicolumn{4}{|c|}{2 female (50\%) \& 2 male ( $50 \%)$} \\
\hline & Location: & \multicolumn{4}{|c|}{1 Maxilla (25\%) \& 3 Mandible (75\%) } \\
\hline & Type: & \multicolumn{4}{|c|}{1 Unicystic Ameloblastoma \& 3 Variant Type Ameloblastoma } \\
\hline
\end{tabular}

\section{Case 2/ Variant Ameloblastoma}

This case was presenting a variant type of ameloblastoma in the left mandible of 31 years female. The patient claimed to have a swelling of chin and halitosis for many years. Initially, it was small, but its sized increased gradually. She went for a traditional massage that worsened the swelling. She had loose teeth at the posterior arch of the left quadrants surrounding area of the swelling, which subsequently extracted. However, her socket never healed. There were palpable small lymph nodes with multiple mucosal ulceration on the buccal cheek. The swelling was firm, not fixed to the skin, no redness and pulsation. The OPG findings showed tumor extended into surrounding tissues and caused bony destruction. It was a multiloculated mass on the left jaw extending into the left maxillary sinus and expanding the buccal cortex of the lower left mandible. (Figure 2). 

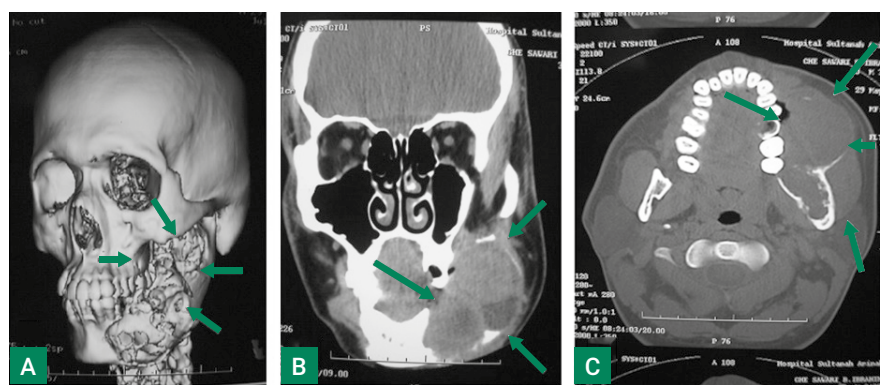

Figure 2. shows the variant Type Ameloblastoma (A) 3D radiograph showed extension of tumour and bony destruction. (B) MRI showed a multiloculated mass of the left jaw causing compression of left maxillary sinus and extension into surrounding soft tissue. (C) MRI scan showed an enlarging mass expanding the buccal cortex of the lower left mandible.

\section{Case 3/ Variant Ameloblastoma}

This case was presenting a variant type of ameloblastoma in the mandible anterior part of 41 years aged male. The patient had swelling over his anterior lower jaw. He complained of numbness of the lower lip. He had loose teeth Grade I. The swelling was painless and non-tender, non-compressible and it was firm. This patient also suffered from a recurrent lesion of ameloblastoma. The radiographs in Figure 3 showed the multiloculated radiolucency extending from 33 to 44 . The well-defined margins were absence with roots resorption adjacent to the lesion. A tumour had also expanded the lingual cortex. (Figure 3).
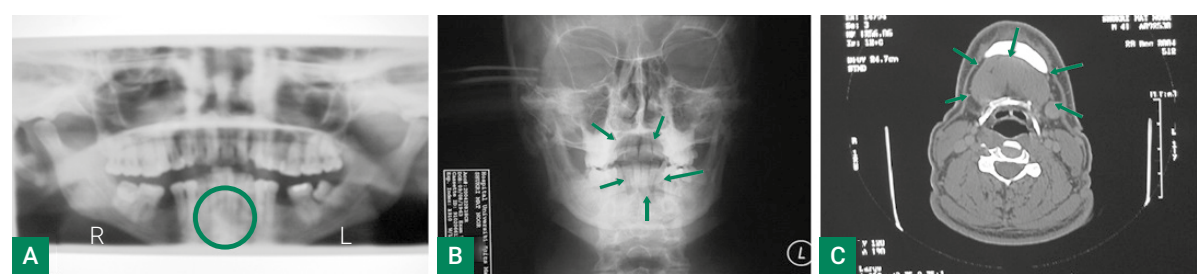

Figure 3. Shows the variant type Ameloblastoma. (A) OPG showed a multiloculated radiolucency extending from 33 to 44 with absence of the well-defined margins accompanied by roots resorptions. (B) Skull X-ray showed an area of radiolucency at the anterior labial segment of the lower mandible. (C) Coronal CT scan showed a large mass arising posterior to the mandible causing expansion of lingual cortex.

\section{Case 4/ Variant Ameloblastoma}

This case was presenting a variant type of ameloblastoma in the right body of the mandible of 23 years aged male. The patient suffered from a painless swelling on the right mandible region. It was bony hard, non-tender, and fixed to underlying structure overlying the skin. He did not complain of loosening teeth, toothache or gum bleeding. Radiographs investigation showed a very well defined uniloculated radiolucency with smooth borders. The displacement of teeth 45 and 46 and slight expansion of cortex were also observed (Figure 4). 



Figure 4. Shows variant type Ameloblastoma. (A) and (C) OPG and MRI showed a very well defined uniloculated radiolucency with smooth borders. There were displacement of teeth 45 and 46 seen in the OPG. Slight expansion of cortex was noted. (B) Skull X-ray showed a radiolucent area at the right angle of mandible with some root resorption of the adjacent teeth.

\section{Discussion}

Ameloblastoma, compounds of two words the English word "amel" which means enamel and the Greek word "blastos" which means germ ${ }^{12}$ and the term was coined by Lucas (1984) ${ }^{14}$. It is a rare structure of benign odontogenic tumor and is manifest by its aggressive local behavior and the high recurrence rate ${ }^{15,16}$ that may influence by certain factors. These factors include the clinicopathological variant of the tumor ${ }^{17,18}$ the anatomic site ${ }^{19,20}$ adequacy of surgery and the histological variant of the ameloblastoma that acts to be of prognostic significance in regards of recurrence. In the maxilla, ameloblastomas occurred at 22\%, where the canine and antral regions of the upper jaw are the most localized area. Moreover, ameloblastomas occurred in the mandible at $80 \%$, where $70 \%, 20 \%$ and $10 \%$ found in the ascending ramus or the molars region and the premolar region, and the anterior region respectively ${ }^{21,22}$. However, it seldom affects the soft tissue (peripheral ameloblastoma) ${ }^{23}$. In addition, about $10-15 \%$ of ameloblastomas associated with a non-erupted tooth ${ }^{22}$.

Ameloblastomas occur with higher frequency in the third or fourth decade of life. Besides, the average age at diagnosis is 34 years with a range of five to 74 years, except in the case of the unicystic variety, which was diagnosed amidst the ages of 20 and 30 years, albeit these case were reported in children ${ }^{21,24,25}$.

The routine radiographic examination acts as an important tool in the discovering of Ameloblastoma coinciding with a clinically observed developing mass. However, in most cases, a unilocular or multilocular radiolucency with a honeycomb or soap bubble appearance, is the characteristic features of ameloblastomas ${ }^{26}$. 
Clinical and radiological features of four cases of ameloblastomas were described in this study. These cases presented with variant types of ameloblastoma except one case with unicystic ameloblastoma. The results of the current study are in accord with those reported previously ${ }^{21,24,25}$ with the age range 23-41 years and average 30.5 years. Also, the previous study revealed that ameloblastoma occurred in equal frequency among men and women ${ }^{27}$. Even though, a lower frequency in male than females has been described $22,28,29$.

In the current study, and according to gender, the percentage of patients was equally distributed, 2 female (50\%) and 2 male (50\%) and these percentages are compatible with previous records elsewhere in the world ${ }^{22,26}$.

In this study, the unicystic ameloblastoma lesion occurred at left maxilla, which is compatible with its clinical features with typical clinical findings reported previously in Japan $2009^{30}$. Ito et al. (2009) ${ }^{30}$ reported a case of unicystic ameloblastoma in a 26-year-old male. The patient was suffering from a history of a left maxillary third molar extraction, three years previously. This patient also revealed a well-defined $3.5 \mathrm{~cm}$ diameter radiolucency of the left maxilla. Moreover, the case was confirmed histologically as unicystic ameloblastoma, plexiform type.

The unicystic ameloblastoma patient that reported in this study revealed unilocular, smooth margin, resorbed root of the $1^{\text {st }}$ premolar, expansion of the left palatal arch, severe facial deformity, extension into the nasal septum and paranasal sinuses, marked nasal obstruction and extension into the orbital floor of maxilla bone. The previous report mentioned that the radiographic features of unicystic ameloblastoma are typically unilocular accompanied with the area of radiolucency ${ }^{29}$. Therefore, this lesion is often misdiagnosed as an odontogenic keratocyst or a dentigerous cyst. Konouchi et al. $(2006)^{31}$ carried out contrast-enhanced (CE)-MRI to investigate 13 cases of unilocular, round radiolucent lesions observed by panoramic radiography and/or CT. Konouchi et al. (2006) ${ }^{31}$ investigation approved that unicystic ameloblastoma revealed low signal intensity (SI) on the T1- weighted images and evidently high SI on T2WIs; and relatively thick rim-enhancement with/ without small intraluminal nodules on CE-T1WIs. They considered that CE-MRI to be useful in the diagnosis of unicystic ameloblastoma.

The patient (case 1) with unicystic ameloblastoma reported in this study showed symptomatic swelling of the left posterior maxilla of a 27-year-old female. However, the most frequent primary site of this lesion is the angle of the mandible and commonly occurs at a younger age group of 1 st and 2 nd decade of life with a prominent preponderance in the male. So, it is not possible to conclude age and location of the lesion due to the limited number of this study. Unicystic ameloblastoma classically contains a tooth and appears as a dentigerous cyst in radiology. These radiological and histological criteria's presented in (case 1) patient. This patient was suffering from the dentigerous cyst, which characterized by non-tender swelling of the palatal region, no bleeding, and ulceration, teeth mobility adjacent to the area of swelling, nasal blockage, and rhinorrhea epiphora. It is often difficult to differentiate between some lesions that occur in the jaw because they have a similar radiographical appearance. In this patient, the radiograph technique approved its ability to investigate the Unicystic ameloblastoma as well as the previous dentigerous cyst, which appeared at the same site. 
In this study, the variant type of ameloblastoma presented in the mandible of the three others patients. The radiograph investigation revealed multiloculated and uninoculated radiolucency in the patients $\mathrm{G} 15 / 04$ \& G9/05 and G25/03 respectively. The clinical and radiographical features of these cases are compatible to that mentioned in previously published cases ${ }^{1,8,9}$.

The radiological features of ameloblastoma's lesions revealed thin cortex of the buccal-lingual plane and enormous mass. Characteristically, the lesions showed a "soap bubble" or "honeycomb" appearance multilocular cystic ${ }^{32,33}$.

The prominent clinical signs appeared on case 2 , case 3 , case 4 patients were a swelling in the jaws and the first step in diagnosis was panoramic radiography. Accordingly, PMG considered as a preferred technique for early diagnosis even though it only reveals the re-interfaces between a tumor and healthy bone. However, MRI used in this study and it was a necessity in the confirmation of the diagnosis and identifies the interfaces between tumor and normal soft tissue such as the lesion contours, contents, and extension into the soft tissues that plain radiographs cannot be catch it. The MRI can show both types of interface the coronal and axial views, while only the axial view is seen in contrast-enhanced CT images ${ }^{34}$. Both MRI and CT have ability for detecting the cystic component of the tumor and imaging papillary projections inside the cystic cavity. The exact content of maxillary ameloblastomas can identify by MRI and thus determine the prognosis for surgery ${ }^{13,15}$. The posterior mandible is the most common site of ameloblastoma that associated with impacted teeth and follicular cysts. In advanced cases, expansion of the cortical plates accompanied with scalloped margins, perforations, and resorption of the affected tooth occurs. Radiographically an ameloblastoma may be mistaken for an odontogenic keratocyst, aneurysmal bone cyst, fibrosarcoma, or a giant cell tumor. The invasiveness nature and a rare chance of metastases of ameloblastomas; the tumor have been subject to the definition from a benign odontogenic epithelial tumor to a slow-growing malignant tumor ${ }^{35}$. If ever metastases were delivered by an ameloblastoma, the most common sites are the lung $(76.7 \%)$, followed by regional lymph nodes (37.8 \%), pleura (16.2\%), vertebrae (13.5\%), skull (10.8\%), diaphragm ( $8.1 \%)$, liver and parotid (5.4\%) and, even more rarely, the spleen and the kidney ${ }^{36,37}$. The metastasis is probably a result of tumor cells associated with surgery, particularly in cases having undergone multiple operations due to recurrences. This aspect is being discussed in this study as one of the patients showed recurrence. The three variants of the benign ameloblastoma, are designated as solid or multicystic, unicystic and periph$\mathrm{era}^{9,38}$. The solid variety has the highest propensity for local infiltration and therefore the highest potential for recurrence ${ }^{9}$. The anatomic site should be considered as one of the important factor in the recurrence of ameloblastoma ${ }^{39}$. Up to $95 \%$ of ameloblastomas occur in the mandible. The dense cortical bone of the mandible prevents the tumor from spreading extensively for several years, however, its spreading in the central cancellous bone is beyond the radiographic margins of the tumor ${ }^{40}$. Complete surgical removal of ameloblastomas lesions needs a careful assessment of the anatomic extent of the tumor. The lesions that are completely intraosseous can be adequately assessed with standard radiography. Radiologically, the ameloblastoma lesions are expansile, with thinning of cortex of the buccal-lingual plane. The Variant Type of Ameloblastoma examined in the present study by 3D radiograph, MRI and MRI scan showed extension 
of tumour and bony destruction; a multiloculated mass of the left jaw causing compression of left maxillary sinus and extension into surrounding soft tissue and an enlarging mass expanding the buccal cortex of the lower left mandible respectively. Finally, the histological variant of the ameloblastoma has been suggested to be of prognostic significance in terms of recurrence. The multilocular ameloblastomas have higher recurrence rates than unilocular ones. Since ameloblastomas infiltrate within the cancellous spaces more, the tumor margin goes beyond the apparent clinical and radiographic margin. The attempts to remove the tumor by curettage may leave small tumor islands in bone, which may later occur as recurrences ${ }^{41}$.

In conclusions, radiologic examination recognized the features of ameloblastomas lesion's including location, density, relation to the tooth, and margin accompanied with clinical data, generally aids in the narrowing of the differential diagnosis and is necessary for early diagnosis of ameloblastoma. However, in young people, the diagnosis remains in doubt after clinical signs and a biopsy is needed. A Long-term follow-up at regular intervals after surgery is recommended.

\section{References}

1. Becelli R, Carboni A, Cerulli G, Perugini M, Iannetti G. Mandibular ameloblastoma: analysis of surgical treatment carried out in 60 patients between 1977 and 1998. J Craniofac Surg. 2002 May;13(3):395-400; discussion 400

2. Iordanidis S, Makos C, Dimitrakopoulos J, Kariki H. Ameloblastoma of the maxilla - case report. Aust Dent J. 1999 Mar;44(1):51-5.

3. Nakamura N, Mitsuyasu T, Higuchi Y, Sandra F, Ohishi M. Growth characteristics of ameloblastoma involving the inferior alveolar nerve: a clinical and histopathologic study. Oral Surg Oral Med Oral Pathol Oral Radiol Endod. 2001 May;91(5):557-62.

4. Hollows P, Fasanmade A, Hayter JP. Ameloblastoma - a diagnostic problem. Br Dent J. 2000 Mar $11 ; 188(5): 243-4$.

5. Sirichitra V, Dhiravarangkura P. Intrabony ameloblastoma of the jaws. An anaylsis of 147 Thai patients. Int J Oral Surg. 1984 Jun;13(3):187-93.

6. Tan W T L, The L Y, Ho K H, Lee ST. Mandibular ameloblastoma in Singapore - A 10 year review. Ann Acad Med Singapore. 1986 Jul;15(3):378-83

7. Kameyama Y, Takehana S, Mizohata M, Nonobe K, Hara M, Kawai T, et al. Aclonicopathological study of ameloblastomas. Int J Oral Maxillofac Surg. 1987 Dec;16(6):706-12.

8. Cawson RA, Odell EW. Cawson's essentials of oral pathology and oral medicine. 7th ed. Churchill Livingstone; 2002. Chapter 17: Oral cancer.

9. Yaacob H. The radiographic appearance of ameloblastoma in Malaysians. Singapore Med J. 1991 Feb;32(1):70-2

10. $\mathrm{Ng} \mathrm{KH}$, Siar $\mathrm{CH}$, Chuah $\mathrm{C} \mathrm{H}$. Ameloblastoma in Malaysian children. Asian J Oral Maxillofac Surg.1989;1:57-62.

11. $\mathrm{Ng} \mathrm{KH}$, Siar $\mathrm{CH}$. Peripheral ameloblastoma with clear cell differentiation. Oral Surg Oral Med Oral Pathol. 1990 Aug;70(2):210-3

12. Siar $\mathrm{CH}, \mathrm{Ng} \mathrm{KH}$. Ameloblastoma in Malaysia-25 years review. Ann Acad Med Singapore. 1993 Nov;22(6):856-60 
13. Reichart PA, Philipsen HP, Sonner S. Ameloblastoma: Biological Profile of 3677 Cases. Oral Oncology, Eur J Cancer B Oral Oncol. 1995 Mar;31B(2):86-99.

14. Lucas RB. Pathology of tumours of the oral tissues. 4th ed. Edinburgh: Churchill Livingstone; 1984. p.31-59.

15. Brazis PW, Miller NR, Lee AG, Holliday MJ. Neuro-ophthalmologic aspects of ameloblastoma. Skull Base Surg. 1995;5(4):233-44.

16. Jordan RCK, Speight PM. Current concepts of odontogenic tumours. Diagn Histopathol. 2009;15(6):303-10.

17. William TP. Management of ameloblastoma: A changing perspective. J Oral Maxillofac Surg. 1993 Oct;51(10):1064-70.

18. Gardner DG. Controversies in the nomenclature, diagnosis and treatment of ameloblastoma. In: Worthington P, Evans JR, editors. Controversies in oral and maxillofac surgery. Philadelphia, PA Saunders; 1994. p.362.

19. Gardner DG, Pecak AM. The treatment of ameloblastoma based on pathologic and anatomic principle. Cancer. 1980 Dec 1;46(11):2514-9.

20. Collings SJ, Harrison A. Recurrent Ameloblastoma? An historic case report and a review of literature. Br Dent J. 1993 Mar 20;174(6):202-6.

21. Torres-Lagares D, Infante-Cossío P, Hernández-Guisado JM, Gutiérrez-Pérez JL. Mandibular ameloblastoma. A review of the literature and presentation of six cases. Med Oral Patol Oral Cir Bucal. 2005 May-Jul;10(3):231-8.

22. Hollows P, Fasanmade A, Hayter JP. Ameloblastoma -- a diagnostic problem. Br Dent J. 2000 Mar $11 ; 188(5): 243-4$.

23. Ogunsalu C, Daisley H, Henry K, Bedayse S, White K, Jagdeo B, et al. A new radiological classification for ameloblastoma based on analysis of 19 cases. West Indian Med J. 2006 Dec;55(6):434-9.

24. Tozaki M, Hayashi K, Fukuda K. Dynamic multislice helical CT of maxillomandibular lesions: distinction of ameloblastomas from other cystic lesions. Radiat Med. 2001 Sep-Oct;19(5):225-30.

25. Artés-Martínez MJ, Prieto-Rodríguez M, Navarro-Hervás M, Peñas-Pardo L, Camañas-Sanz A, Vaquero de la Hermosa MC, et al. Ameloblastoma. Diagnosis by means of FNAB. Report of two cases. Med Oral Patol Oral Cir Bucal. 2005 May-Jul;10(3):205-9.

26. Small IA, Waldron CA. Ameloblastoma of the jaws. Oral Surg Oral Med Oral Pathol. 1955 Mar;8(3):281-97.

27. Small IA. Recurrent ameloblastoma, 25 years after hemimandibulectomy. Oral Surg Oral Med Oral Pathol. 1956 Jul;9(7):699-706.

28. Adekeye EO. Ameloblastoma of the jaws: a survey of 109 Nigerian patients. J Oral Surg. 1980 Jan;38(1):36-41.

29. Gardner AF, Apter MB, Axelrod JH. A study of twenty-one instances of ameloblastoma, a tumor of odontogenic origin. J Oral Surg Anesth Hosp Dent Serv. 1963 May;21:230-7.

30. Ito S, Mandai T, Ishida K, Kitamura N, Deguchi H, Hata T, et al. Unicystic ameloblastoma of the maxilla : A case report. Kawasaki Med J. 2009;35(1):95-8.

31. Konouchi H, Asaumi J, Yanagi Y, Hisatomi M, Kawai N, Matsuzaki H, et al. Usefulness of contrast enhanced-MRI in the diagnosis of unicystic ameloblastoma. Oral Oncol. 2006 May;42(5):481-6.

32. Rampton P. Teeth and jaws. In: Sutton D, editor. Textbook of radiology and imaging. Philadelphia: Churchill-Livingstone; 1998. p.1388-9.

33. Gümgüm S, Hoşgören (2005). Clinical and radiologic behaviour of ameloblastoma in 4 cases. J Can Dent Assoc. 2005 Jul-Aug;71(7):481-4. 
34. Cihangiroglu M, Akfirat M, Yildirim H. CT and MRI findings of ameloblastoma in two cases. Neuroradiology. 2002 May;44(5):434-7.

35. Moe H, Clausen F, Philipsen HP. The ultrastructure of the simple ameloblastoma. Acta Pathol Microbiol Scand. 1961;52:140-54

36. Shatkin S, Hoffmeister FS. Ameloblastoma: a rational approach to therapy. Oral Surg Oral Med Oral Pathol. 1965 Oct;20(4):421-35.

37. Ueno S, Mushimoto K, Shirasu R. Prognostic evaluation of ameloblastoma based on histologic and radiographic typing. J Oral Maxillofac Surg. 1989 Jan;47(1):11-5.

38. Shafer WG, Hine MF, Levy BM. A Textbook of Oral Pathology. 4th ed. Saunders; 1983. Chapter 4: Cysts and Tumours of Odontogenic Origin.

39. El-Sissy NA. Immunohistochemical detection of p53 protein in ameloblastomas types. East Mediterr Health J. 1999 May;5(3):478-89

40. Vered M, Shohat I, Buchner A. Epidermal growth factor receptor expression in ameloblastoma. Oral Oncol. 2003 Feb;39(2):138-43.

41. Vogelstein B, Kinzler KW. The genetic basis of human cancer. $2^{\text {nd }}$ ed. New York: McGraw Hill; 2002. Chapter 23: Syndrome by David Malkin. p.387-401. 